\title{
О.Я. Старкова
}

\section{РЕГИОНАЛЬНЫЙ АСПЕКТ ЭФФЕКТИВНОГО ИСПОЛЬЗОВАНИЯ ЗЕМЛИ В СЕЛЬСКОМ ХОЗЯЙСТВЕ}

\begin{abstract}
Рассмотрена роль земельных ресурсов как основного фрактора сельскохозяйственного производства. Определены основные задачи землепользования. Обосновывается необходимость рационального использования земель сельскохозяйственного назначения. Проведен анализ различных подходов к пониманию экономической эффективности использования земельных ресурсов. Сделан вывод о взаимосвязи экономической эффективности использования земельных ресурсов с сохранением плодородия почв и экологической безопасностью. Приведена классификация показателей эффеектиности использования земельных ресурсов в сельском хозяйстве. Перечислены стоимостные показатели эффективности использования земельных ресурсов. Проанализированы мнения отдельных исследователей относительно признания показателей эффективности использования земельных ресурсов к основным показателям. Рассмотрены особенности частных и относительных показателей эффективности использования земельных ресурсов. Обосновывается невозможность применения одинаковых показателей эффективности к различным организационно-правовым формам хозяйствования на земле. Названы меры налогового стимулирования и иных форм государственной поддержки развития землепользования в сельском хозяйстве. Проведен анализ посевных площадей сельскохозяйственных культур в Пермском крае. Сделан вывод о недостаточности мер поддержки со стороны федеральных и региональных органов власти в области сельского хозяйства и не обеспечивающих эффективность землепользования. Проведен анализ производства сельскохозяйственной продукции в расчете на 1 га посевных площадей. Рассмотрена динамика урожайности сельскохозяйственных культур как показатель эффективности использования земельных ресурсов. Сделаны выводы о внесении минеральных и органических удобрений под посевы в сельскохозяйственных организациях. Приведены доказательства снижения эффективности использования земельных ресурсов в сельском хозяйстве Пермского края. Сделаны предложения органам власти по повышению эффективности использования земельных ресурсов в сельскохозяйственном производстве.

Ключевые слова: продовольственная безопасность, продукция растениеводства, посевные площади, урожайность.
\end{abstract}

Введение. Аграрное производство обеспечивает импортозамещение в сфере производства продуктов питания и сельскохозяйственного сырья. Основным средством производства в сельском хозяйстве является земля, использование которой в растениеводстве и животноводстве имеет свои особенности, не свойственные другим отраслям. На особой роли земли как средства производства останавливаются в своих работах А.М. Магомедов и А.Г. Бучаев, которые определили основные задачи землепользования, заключающиеся в максимальном обеспечении потребностей населения и производства в сельскохозяйственной продукции, сохранение качества земельных ресурсов и экологической безопасности [1, с. 77$]$.

(C) Старкова О.Я., 2017

Старкова Ольга Яковлевна - канд. экон. наук, доцент кафедры финансов, кредита и экономического анализа ФГБОУ ВО «Пермская государственная сельскохозяйственная академия имени Д.Н. Прянишникова», e-mail: klimova377@ mail.ru. 
Российская Федерация обладает огромной территорией, но проблема рационального использования земель сельскохозяйственного назначения стоит достаточно остро, так как, по сведениям Т.А. Емельяновой и Д.В. Новикова, 40 млн га не засевается и значительная часть из них зарастает кустарником [2, с. 20].

Под экономической эффективностью использования земельных ресурсов И.А. Артамонова понимает такой уровень организации производства, который характеризуется количеством продукции, получаемой с единицы земельной площади [3, с. 21]. Нельзя не согласиться с уточнением, которое делает данный автор о том, что экономическая эффективность связана не только с увеличением выхода продукции и повышением ее качества, но и с решением экологических проблем, сохранением плодородия почвы.

Эффективное использование земельных ресурсов, по мнению Л.А. Киркоровой и А.А. Михайлова, должно обеспечить рост производства валовой продукции с единицы земельной площади [4, с. 39].

Показатели, характеризующие экономическую эффективность использования земли в сельском хозяйстве, как считают Е.Ю. Меркулова и Г.Б. Вязов, можно подразделить на стоимостные и натуральные [5, с. 55].

И.А. Артамонова к стоимостным показателям относит объем валовой продукции на один га сельскохозяйственных угодий, производство валовой продукции растениеводства в расчете на одного работника, а к натуральным показателям - урожайность культур, производство продукции на 100 га сельскохозяйственных угодий [3]. Соглашаясь с таким подходом, многие авторы в числе данных показателей выделяют показатели, которые, по их мнению, являются основными. К таковым М.А. Мусаев относит: стоимость валовой продукции в расчете на 1 га площади, урожайность сельскохозяйственных культур, рентабельность производства продукции, дифференциальный доход, окупаемость затрат на земельные ресурсы и т.д. [6, с. 14].

С другой стороны, Е.Ю. Меркулова и Г.Б. Вязов основным показателями считают землеотдачу, землеемкость, землерентабельность, объем валовой добавленной стоимости по видам экономической деятельности $[5$, с. 55]. Кроме того, они перечисляют частные показатели, например, удельный вес пашни в структуре сельскохозяйственных угодий, количество внесенных минеральных удобрений, урожайность сельскохозяйственных культур и т.д.

Отдельно И.А. Артамонова останавливается на относительных показателях, характеризующих распаханность сельскохозяйственных угодий, долю удобренной площади ко всей посевной площади, долю сельскохозяйственных угодий к общей площади земли. Кроме того, данный автор предлагает учитывать организационно-правовую форму хозяйствования на земле, так как в крестьянских (фермерских) хозяйствах и личных подсобных хозяйствах граждан отдельные показатели экономической эффективности использования земли не могут быть применены. 
Т.Г. Ханбаев и Л.С. Даибова обобщающим показателем эффективности землепользования считают выход товарной продукции в сопоставимых и текущих ценах, приходящейся на 100 га сельскохозяйственных угодий или пашни [7, с. 33].

Данное многообразие подходов к классификации показателей эффективности использования земельных ресурсов в сельском хозяйстве позволяет проводить всесторонний анализ процессов, происходящих в аграрном секторе экономики и разрабатывать предложения по совершенствованию землепользования.

Обязательным условием развития аграрного производства, базирующегося на использовании земли, является государственная поддержка, значительным элементом которой следует считать льготное налогообложение [8, с. 71]. Сельскохозяйственные производители имеют право использовать специальный налоговый режим, применение которого обеспечивает снижение налоговой нагрузки. В аграрном секторе экономики значительную часть продукции производит малый и средний бизнес, которому в соответствии с налоговой политикой региональных органов власти могут быть предоставлены дополнительные преимущества, например, «налоговые каникулы» [9, с. 67].

Однако в Российской Федерации невозможно ограничится только налоговым стимулированием. Большая протяженность земельных угодий и плохая транспортная доступность делает обязательным, по мнению О.Д. Ермолаенко, развитие инфраструктуры, что невозможно без участия государства [10, с. 210].

Прибыль сельскохозяйственных предприятий зависит от плодородия обрабатываемых земель [11, с. 52]. Государство субсидирует мелиоративные мероприятия и внесение удобрений, тем самым способствует сохранению качества земельных угодий [12, с. 87$]$.

Объекты и методы исследования. Объектом исследования являются земельные ресурсы Пермского края, используемые в сельском хозяйстве региона. При написании статьи нашел применение монографический метод исследования, обеспечивающий использование комплексно-функционального анализа для изучения взаимосвязей с помощью аналитических показателей.

Результаты и обсуждения. Эффективное землепользование должно обеспечивать вовлечение в обработку дополнительных земельных угодий и способствовать сохранению плодородия почвы. Рассмотрим, как изменились показатели посевных площадей в Пермском крае за период с 2011 по 2015 год (табл. 1).

Данные табл. 1 свидетельствуют о неблагоприятном положении с размером посевных площадей в Пермском крае. За период с 2011 до 2015 год общий размер посевов сократился на 36 тыс. га, или на 4,5\%. Сокращения в основном затронули посевные площади под зерновыми и зернобобовыми культурами и в меньшей степени - под кормовыми культурами. Крайне 
незначительно выросли площади под техническими культурами, картофелем и овощами открытого грунта. Снижение размера посевных площадей позволяет сделать вывод о том, что меры, предпринимаемые федеральными и региональными органами власти РФ, не оказали положительного воздействия и не обеспечивают условия для реализации программы импортозамещения в аграрной сфере.

Таблица 1

Посевные площади сельскохозяйственных культур в Пермском крае, тыс. га

\begin{tabular}{|l|c|c|c|c|c|}
\hline \multicolumn{1}{|c|}{ Показатель } & 2011 г. & 2012 г. & 2013 г. & 2014 г. & 2015 г. \\
\hline Всего & 793,2 & 744,5 & 736,0 & 739,0 & 757,2 \\
\hline В том числе: & & & & & \\
зерновые и зернобобовые & 282,0 & 254,1 & 268,1 & 243,8 & 248,3 \\
технические культуры & 4,4 & 4,4 & 4,8 & 5,6 & 4,6 \\
картофель & 42,0 & 43,1 & 42,8 & 42,2 & 42,2 \\
овощи & 7,7 & 7,9 & 7,9 & 8,0 & 8,1 \\
кормовые культуры & 457,1 & 432,0 & 412,3 & 439,4 & 454,0 \\
\hline
\end{tabular}

В условиях сокращения посевных площадей еще более остро встает вопрос об их эффективном использовании, обобщающим показателем которого является производство сельскохозяйственной продукции в расчете на 1 га посевных площадей, рассчитанный на основании данных Территориального органа Федеральной службы государственной статистики по Пермскому краю (табл. 2) [13, с. 100].

Таблица 2

Производство сельскохозяйственной продукции в расчете на 1 га посевных площадей в Пермском крае, т

\begin{tabular}{|l|c|c|c|c|c|}
\hline \multicolumn{1}{|c|}{ Показатель } & 2011 г. & 2012 г. & 2013 г. & 2014 г. & 2015 г. \\
\hline Зерно & 0,56 & 0,43 & 0,37 & 0,49 & 0,40 \\
\hline Картофель & 0,85 & 0,82 & 0,75 & 0,73 & 0,67 \\
\hline Овощи & 0,30 & 0,31 & 0,32 & 0,31 & 0,29 \\
\hline Скот и птица на убой & 0,10 & 0,11 & 0,10 & 0,10 & 0,10 \\
\hline Молоко & 0,61 & 0,65 & 0,63 & 0,64 & 0,64 \\
\hline
\end{tabular}

Анализируя данные табл. 2, можно сказать, что за период с 2011 по 2015 год производство продукции растениеводства в расчете на 1 га посевной площади сокращается, производство скота и птицы на убой не претерпело изменений, а производство молока несколько выросло. Особенно заметно снижение производства зерна и картофеля, которое составило соответственно (в расчете на 1 га посевных площадей) 29 и $21 \%$. Увеличение производства молока значительно ниже - только $5 \%$. В целом можно констатировать, что эффек- 
тивность использования земельных ресурсов в соответствии с этим показателем снизилась.

На снижение объемов производства основных видов растениеводческой продукции сказалось не только сокращение посевных площадей, но и снижение урожайности (табл. 3).

Таблица 3

Урожайность сельскохозяйственных культур в Пермском крае, ц/га

\begin{tabular}{|l|c|c|c|c|c|}
\hline \multicolumn{1}{|c|}{ Показатель } & 2011 г. & 2012 г. & 2013 г. & 2014 г. & 2015 г. \\
\hline Зерно и зернобобовые культуры & 16,3 & 13,0 & 12,9 & 16,0 & 13,8 \\
\hline Пшеница & 14,6 & 11,7 & 11,6 & 14,3 & 13,3 \\
\hline Картофель & 160,7 & 142,0 & 130,7 & 128,7 & 124,3 \\
\hline Овощи & 308,8 & 287,3 & 301,8 & 287,1 & 282,9 \\
\hline
\end{tabular}

Данные табл. 3 свидетельствуют о том, что урожайность основных сельскохозяйственных культур за анализируемый период снизилась. В наибольшей степени это относится к картофелю (снижение составило 22,7 \%) и зерновым и зернобобовым культурам $(15,3 \%)$ и в меньшей степени - к пшенице $(8,9 \%)$ и овощам открытого грунта $(8,4 \%)$. Сложившаяся тенденция снижения урожайности характерна только для картофеля, по остальным культурам этот показатель колебался то в лучшую, то в худшую сторону. Например, урожайность зерна и зернобобовых культур, в том числе пшеницы, в 2012 и 2013 годах снизилась, а в 2014 году выросла на 24 \%. Безусловно, урожайность сельскохозяйственных культур во многом определяется погодными условиями, но большое значение имеет технология выращивания, в том числе внесение удобрений. Динамика использования минеральных и органических удобрений отражена в табл. 4.

Таблица 4

Внесение удобрений под посевы в сельскохозяйственных организациях в Пермском крае

\begin{tabular}{|l|c|c|c|c|c|}
\hline \multicolumn{1}{|c|}{ Показатель } & 2011 г. & 2012 г. & 2013 г. & 2014 г. & 2015 г. \\
\hline Минеральные удобрения всего, тыс. т & 11,4 & 10,8 & 8,7 & 8,9 & 7,6 \\
\hline В том числе на 1 га посева, кг & 16,9 & 17,5 & 14,4 & 15,3 & 13,1 \\
\hline Уд. вес удобренной площади, \% & 38 & 37 & 33 & 35 & 30 \\
\hline Органические удобрения всего, тыс. т & 1087 & 986 & 996 & 1066 & 1156 \\
\hline В том числе на 1 га посева, кг & 1,6 & 1,6 & 1,7 & 1,8 & 2,0 \\
\hline Уд. вес удобренной площади, \% & 3 & 3 & 3 & 5 & 4 \\
\hline
\end{tabular}

Анализ данных табл. 4 показывает, что внесение минеральных удобрений под посевы в сельскохозяйственных организациях с 2011 по 2015 год снизилось на 3,8 кг на 1 га (на 22,5 \%); удельный вес удобренной площади сокра- 
тился с 38 \% в 2011 году до $30 \%$ в 2015 году. Внесение органических удобрений, напротив, увеличилось на 69 тыс. т, что составило дополнительно 0,4 т на 1 га посевов. Однако удельный вес площади, удобренной органическими удобрениями, крайне мал и даже с учетом увеличения в 2015 году он составил только $4 \%$ от общего количества, что не могло компенсировать сокращение внесения минеральных удобрений и послужило одной из причин снижения урожайности сельскохозяйственных культур. Снижение доли удобренной земельной площади подтверждает вывод о снижении эффективности использования земли в сельском хозяйстве Пермского края.

Bbbodb. Таким образом, можно сделать вывод о том, что в Пермском крае за период с 2011 по 2015 год количество посевных площадей сократилось на $36 \%$. Эффективность использования земли снизилась, о чем свидетельствует сокращение производства продукции растениеводства в расчете на 1 га посевных площадей. Негативным показателем является имевшее место снижение урожайности основных сельскохозяйственных культур, что было вызвано, в том числе, и снижением внесения минеральных удобрений под посевы в сельскохозяйственных организациях.

Необходимость обеспечения продовольственной безопасности за счет осуществления процесса импортозамещения требует принятия мер органами власти Пермского края по предотвращению дальнейшего выведения из оборота сельскохозяйственных земель. Кроме того, Пермский край обладает уникальными возможностями по улучшению качества сельскохозяйственных угодий за счет внесения удобрений, так как на территории Прикамья имеются мощности по добыче калийных удобрений и производству минеральных удобрений. Необходимо разработать и внедрить механизм, стимулирующий производителей удобрений реализовывать свою продукцию региональным аграриям на более льготных условиях. Реализация подобных мер послужит основанием для повышения эффективности использования земельных ресурсов в сельском хозяйстве Пермского края.

\section{Список литературы}

1. Магомедов А.М., Бучаев А.Г. Использование земельных ресурсов региона на основе логистики // Экономика сельского хозяйства России. 2013. - № 5. - С. 76-82.

2. Емельянова Т.А., Новиков Д.В. Земельные отношения и землеустройство // Экономика сельского хозяйства России. - 2013. - № 1. - С. 11-21.

3. Артамонова И.А. Методологические подходы к оценке эффективности использования земель сельскохозяйственного назначения // Агропродовольственная политика России. - 2014. - № 8. - С. 21-23.

4. Киркорова Л.А., Михайлов А.А. Использование земельных ресурсов фермерами // Экономика сельского хозяйства России. - 2008. - № 5 - - С. 37-42. 
5. Меркулова Е.Ю., Вязов Г.Б. Методика оценки эффективности использования земельных ресурсов региона // Вестник Тамбовского университета. Гуманитарные науки. - 2015. - № 2 (142). - С. 55-65.

6. Мусаев Т.Г. Экономическая эффективность использования земельных ресурсов в условиях рыночных отношений [Электронный ресурс] // Региональные проблемы преобразования экономики. - 2010. - № 1. - URL: http://www.rppe.ru/wp-content/uploads/2011/05/musaev-ma.pdf (дата обращения: 02.02.2017).

7. Ханбаев Т.Г., Даибова Л.С. Эффективность использования земли в сельском хозяйстве с применением системы показателей // Горное сельское хозяйство. - 2016. - № 1. - С. 31-35.

8. Старкова О.Я. Налоговое бремя сельскохозяйственных предприятий // Пермский аграрный вестник. - 2014. - № 3 (7). - С. 70-77.

9. Старкова О.Я. Государственное регулирование инновационного развития сельскохозяйственного производства // Пермский аграрный вестник. 2015. - № 3 (11). - С. 65-69.

10. Ермолаенко О.Д. Эффективность государственной поддержки сельскохозяйственного производства // Политематический сетевой электронный научный журнал Кубанского аграрного университета. - 2017. - № 125. C. 210-222.

11. Бахтеев Ю.Д., Кудюшева 3.А., Бахтеева М.Р. Воспроизводство земельных ресурсов в сельском хозяйстве // Экономика сельского хозяйства России. - 2014. - № 9. - С. 52-56.

12. Старкова О.Я. Конкуренция и государственная поддержка как условие развития аграрного сектора экономики // Пермский аграрный вестник. 2015. - № 1 (9). - С. 86-91.

13. Пермский край в цифрах. 2016: Краткий статистический сборник / Террит. орган Федер. службы гос. статистики по Пермскому краю. - Пермь, 2016. -179 c.

\section{References}

1. Magomedov A.M., Buchaev A.G. Ispol'zovanie zemel'nykh resursov regiona na osnove logistiki [Use of land resources of the region on the basis of logistics]. Ekonomika sel'skogo khoziaistva Rossii, 2013, no. 5, pp. 76-82.

2. Emel'ianova T.A., Novikov D.V. Zemel'nye otnosheniia i zemleustroistvo [Land relations and land management]. Ekonomika sel'skogo khoziaistva Rossii, 2013, no. 1, pp. 11-21.

3. Artamonova I.A. Metodologicheskie podkhody $\mathrm{k}$ otsenke effektivnosti ispol'zovaniia zemel' sel'skokhoziaistvennogo naznacheniia [Methodological approaches to assessing the efficiency of agricultural land use]. Agroprodovol'stvennaia politika Rossii, 2014, no. 8, pp. 21-23. 
4. Kirkorova L.A., Mikhailov A.A. Ispol'zovanie zemel'nykh resursov fermerami [Use of land resources by farmers]. Ekonomika sel'skogo khoziaistva Rossii, 2008, no. 5, pp. 37-42.

5. Merkulova E.Iu., Viazov G.B. Metodika otsenki effektivnosti ispol'zovaniia zemel'nykh resursov regiona [Methodology for assessing the effectiveness of land resources use in the region]. Vestnik Tambovskogo universiteta. Gumanitarnye nauki, 2015, no. 2, vol. 142, pp. 55-65.

6. Musaev T.G. Ekonomicheskaia effektivnost' ispol'zovaniia zemel'nykh resursov v usloviiakh rynochnykh otnoshenii [Economic efficiency of land resources use under the conditions of market relations]. Regional'nye problemy preobrazovaniia ekonomiki, 2010, no. 1, pp. 14. Available at: http:/www.rppe.ru/wp-content/uploads/2011/05/musaev-ma.pdf (accessed 02 February 2017).

7. Khanbaev T.G., Daibova L.S. Effektivnost' ispol'zovaniia zemli v sel'skom khoziaistve s primeneniem sistemy pokazatelei [Efficiency of land use in agriculture with the application of the system of indicators]. Gornoe sel'skoe khoziaistvo, 2016, no. 1, pp. 31-35.

8. Starkova O.Ia. Nalogovoe bremia sel'skokhoziaistvennykh predpriiatii [The tax burden of agricultural enterprises]. Permskii agrarnyi vestnik, 2014, no. 3, vol. 7, pp. 70-77.

9. Starkova O.Ia. Gosudarstvennoe regulirovanie innovatsionnogo razvitiia sel'skokhoziaistvennogo proizvodstva [State regulation of agricultural production innovative development]. Permskii agrarnyi vestnik, 2015, no. 3, vol. 11, pp. 65-69.

10. Ermolaenko O.D. Effektivnost' gosudarstvennoi podderzhki sel'skokhoziaistvennogo proizvodstva [Effectiency of state support for agricultural production]. Politematicheskii setevoi elektronnyi nauchnyi zhurnal Kubanskogo agrarnogo universiteta, 2017, no. 125, pp. 210-222.

11. Bakhteev Iu.D., Kudiusheva Z.A., Bakhteeva M.R. Vosproizvodstvo zemel'nykh resursov $\mathrm{v}$ sel'skom khoziaistve [Land resources reproduction in agriculture]. Ekonomika sel'skogo khoziaistva Rossii, 2014, no. 9, pp. 52-56.

12. Starkova O.Ia. Konkurentsiia i gosudarstvennaia podderzhka kak uslovie razvitiia agrarnogo sektora ekonomiki [Competition and state support as a condition for the agrarian sector of economy development]. Permskii agrarnyi vestnik, 2015, no. 1, vol. 9, pp. 86-91.

13. Permskii krai v tsifrakh 2016: Kratkii statisticheskii sbornik [Perm krai in figures in 2016: A brief statistical digest]. Territorial'nyi organ Federal'noi sluzhby gosudarstvennoi statistiki po Permskomu kraiu. Perm, 2016, 179 p.

Оригинальность $93 \%$

Получено 03.05.2017 Принято 01.06.2017 Опубликовано 30.09.2017 


\section{O.Ya. Starkova}

\section{REGIONAL DIMENSION OF THE EFFECTIVE LAND USE IN AGRICULTURE}

The article reveals the role of land resources as one of the key factors of agriculture. The research defines the key tasks of land use and justifies the need for rational use of land in agriculture. It analyzes various approaches to understanding the essence of economic efficiency in using land resources. The author draws a conclusion on the interrelation of economic efficiency in using land resources and soil conservation and environmental safety. The paper presents the classification of efficiency indicators of using land resources in agriculture and enumerates the cost indicators of their use. It also analyzes the opinions of the researchers concerning the recognition of efficiency indicators of land resources use among other indicators. The research considers the particularities specific and relative indicators of efficiency of land resources use. The author substantiates the impossibility of applying similar indicators to different organizational and legal business patterns. The study states the fiscal stimulus measures and other forms of government support of land-utilization development in agriculture. The article presents the research findings of the analysis of cultivated areas in Perm Krai. The author states the insufficiency of supportive measures on the part of both federal and regional authorities in the field of agriculture, which does not provide the land use efficiency. The research presents the analysis of agricultural productivity on a per hectare basis of cultivated areas. It considers the yield dynamics as a land use efficiency indicator. It also offers the relevance of mineral and organic fertilizing in preparing seedbeds in agricultural organizations. The research proves there is a decrease in the efficiency of land use in the agricultural sphere of Perm Krai. The paper offers certain propositions so as to increase the land use efficiency in agriculture.

Keywords: food security, crop production, cultivated areas, yield.

Olga Ya. Starkova - Candidate of Economic Sciences, Associate Professor, Dept. of Finance, Credit and Economic Analysis, Perm State Agricultural Academy named after D.N. Pryanishnikov, e-mail: klimova377@mail.ru.

Received 03.05.2017 Accepted 01.06.2017 Published 30.09.2017 